\title{
From e-Learning 1.0 to e-Learning 2.0: Threats \& Opportunities for Higher Education Institutions in the Developing Countries
}

By

\author{
${ }^{1}$ G. M. Kundi (PhD), ${ }^{2}$ A. Nawaz $(\mathrm{PhD})$
}

\begin{abstract}
The effective use of information and communication technologies (ICTs) in higher education institutions (HEIs) is a global issue for individual researchers, institutions, governments and societies as a whole. New technologies offer opportunities for the developing countries to resolve their long standing problems of national/international isolation and mass-education. Researchers are posting reports of positive results of eLearning applications around the world; however, using digital gadgets for teaching, learning and education management is neither automatic nor devoid of challenges and problems. There are both development and use problems for the developers, users and institution. Broadly there are three e-Learning systems available to the HEIs: traditional computer-based learning, blended learning and virtual learning with relative merits and demerits but their choice is based on the availability of resources and professionalism. Most of the developing countries (DCs) have started experimenting with traditional and blended systems while developed world is practicing and researching the virtual systems. This paper is an effort to portray a picturesque of the same evolution of e-Learning from e-Learning 1.0 to e-Learning 2.0 in the HEIs of developing states like Pakistan. Critical analyses and argumentation were the research tools used for examination and analysis and to interpret the results of the analysis.
\end{abstract}

Keywords: HEI, ICTs, Traditional, Blended, and Virtual e-Learning, e-Teachers, eStudents e-Administrators.

\section{Introduction}

Information and Communication Technologies (ICTs) are generating a new global economy, which gets its power from technology, fuel from information and knowledge takes the driving seat (Tinio, 2002). These technologies provide the electricity of information-age (Macleod, 2005) to construct an information-society or knowledgeeconomy (Hameed, 2007). However, technological innovations and applications are founded on the education system of a country. For example, any digital initiative is 
fueled by a batch of ICT-professionals to develop and users to apply technologies for organizational objectives (Ezziane, 2007). Given that, it is the education system which helps nations in harnessing ICTs for government, business, agriculture, banking and education by generating a skilled workforce. However, this requires the education system itself to be computerized first and then educate the masses in adopting computers into their informal and formal lives (Nawaz \& Kundi, 2010a; Nawaz, 2012a).

Within education, ICTs have started emerging, for example, in the western European context, it is now common to integrate ICT into logistical, organizational and educational functions of HEIs (Valcke, 2004; Baumeister, 2006) showing that ICTs are changing the nature of work and the workplace for all the university constituents (Ezziane, 2007). Sife et al., (2007) found that ICTs are changing the organization and delivery of higher education because they are adopting alternatives to the traditional classroom pedagogy and developing a variety of e-Learning courses. Research also suggests that ICTs offer new learning opportunities for students e-Learning, develop teacher's professional capabilities (e-Pedagogy) and strengthen institutional capacity (e-Education) and most universities today offer some form of e-Learning (Nawaz et al., 2011c).

\section{From E-Learning 1.0 To E-Learning 2.0: The Evolution}

Blended Learning or e-Learning was a buzzword few years ago "teaching and learning with the aid of computers" (Sendall et al., 2008). The expression $\mathrm{A}^{3}$ (anytime, anywhere and anybody) was the synonym at the inception of e-Learning and the first steps of e-Learning (Crane Beverley, 2009), that includes all forms of electronically supported learning and teaching including education technology or a computer and network enabled transfer of skills and knowledge. Yet, earlier e-Learning was based on conventional methods such as instructional packets delivered to students through assignments evaluated by teachers, on other side, new concept of e-Learning 'eLearning 2.0' places increased emphasis on the social learning and use of social software (Brown et al., 2008). However, the Web we are using today is dramatically changing. Tim O'Reilly (2004) was the first who coined Web 2.0, and its popularity grew within all its applications i.e. use of Weblogs, Wikis, Podcasts, Web Sharing Applications and Social Bookmarking simply known as Social Network, wherein e-Learning 2.0 is the title of bringing the benefits of Web 2.0 to learning. Stephen Downes, was the first who used term e-Learning 2.0, in his article "For all this technology, what is important to recognize is that the emergence of the Web 2.0 is not a technological revolution, it is a social revolution" so eLearning 2.0 assumes that knowledge is socially constructed (Brown et al., 2008).

E-Learning ranges from a supplemental use of computers to entirely depending on ICTs for teaching, learning and education management. However, modern sophisticated uses of e-Learning in some parts of the world has not reached this level instantly rather along the development trajectory of the ICTs themselves. As the computers and communication technologies became more and more advanced and increasingly supportive in the education environment, the e-Learning models grew into more 
sophisticated tools for real e-Teachers, e-Students and e-Administrators (Nawaz \& Kundi, 2010b; Nawaz, 2012b).

Broadly, e-Learning has gone through the following stages over the past decades:

1. In 1970s and 1980s, e-Learning was called computer-assisted learning, computer-based training or technology-based training. Pedagogically, early programs mostly involved electronic page turning and were didactic in approach with transmitted knowledge as the purpose. The teachers used to transmit the knowledge rather than facilitating the learner and learning process (Gray et al., 2003; Dinevski \& Kokol, 2005). (traditional computer-based learning)

2. By the 1990s other forms of educational-media came into market to supplement old e-Learning and brought e-Learning at the public level offering discussions and debates through communication technologies - a kind of "negotiated-knowledge (Gray et al., 2003)." Email and discussion groups are playing key role in this kind of e-Learning (Valcke, 2004). In the late 1990s, innovations in computer hardware, computer software, and Internet technologies introduced a line of education products that established the eLearning industry (Nawaz et al., 2011a). (blended learning)

3. By the end of 1990s, virtual learning environments (VLEs) have emerged with tools and techniques for the course-management and interactivity of teachers and learners through a long line of opportunities particularly, the web-based applications, which enable not to simply deliver knowledge rather empower learners to develop research skills and capitalize on web to "harvest knowledge (Gray et al., 2003)." In contrast to instrumental education, 'Liberal' theory advises to harvest the intellect and develop analytical and critical thinking because liberal education views the search for knowledge as an active and interconnected social activity and not merely a recollection of facts (Nawaz et al., 2011c) (virtual learning). Below Table-1 presents bird eye view of this evolution:

Table: 1.

\begin{tabular}{|l|l|l|}
\hline & e-Learning 1.0 & e-Learning 2.0 \\
\hline Main Concepts & $\begin{array}{l}\text { Courseware, LMS, } \\
\text { Authoring tool }\end{array}$ & $\begin{array}{l}\text { Wiki, Social Networking, Add-inns, } \\
\text { Mash-up. }\end{array}$ \\
\hline Ownership & Top-down, One-way & Bottom-up, Learner Drives, peer learning \\
\hline $\begin{array}{l}\text { Development } \\
\text { Time }\end{array}$ & Long & None \\
\hline Content Size & 60 Minutes & 1 Minute \\
\hline Access Time & Prior to work & During work \\
\hline Delivery & At one time & When you need it \\
\hline Content Access & LMS & Search, RSS feed \\
\hline Drivers & ID & Worker \\
\hline Content Creator & ID & User \\
\hline Training's Role & Gourmet Chef & Food critic \\
\hline
\end{tabular}

\subsection{Traditional Computer-based Learning}

Conventional teaching emphasizes content where course is written around textbooks and teachers teach through lectures and presentations and so design the learning activities 
that the contents could be rehearsed (Dinevski \& Kokol, 2005). Likewise, traditional computer-mediated instruction is based on a certain level of technical rationality and objectivist and behaviorist ideas, which emphasize that knowledge and reality exists out there therefore the pedagogy takes a the learner from basic to applied knowledge and ultimately into practice (Nawaz \& Qureshi, 2010c). In traditional computer-based learning there is low collaboration with teacher-centered learning contexts where there is one-way communication from the teacher to the learner and learning materials are disseminated in print format however, e-Learning is now moving away from the traditional computer based learning (Kundi \& Nawaz, 2010).

\subsection{Blended Learning}

Blended learning is a combination of face to face and computer based teaching and learning or a combination of traditional classroom practice with e-Learning solutions (Tinio (2002). It is a shift from computer-based instruction where students learn from technology, to enabling students to learn with the technology (Young, 2003). Blended learning is also called multi-modal learning. It is a learning facilitation that incorporates different modes of delivery, models of teaching, and learning styles, introduces multiple media to the dialog between the learner and the facilitator (Koo, 2008). Furthermore, blended e-Learning applications within the higher education sector are mushrooming (Nawaz \& Kundi, 2010b).

Since blending refers to the mix of traditional and digital methods of teaching, learning and administration, therefore all the institutes, which are beginning to computerize, come under the general umbrella of blended learning. The research shows that eLearning is enjoying a growing maturity, blending the technology with other forms of delivery such as face-to-face teaching (Gray et al., 2003). However, blended learning is not simply a matter of the combination of face-to-face and online instruction rather it depends on social interaction. Community building and maintenance is an integral part of Blended Learning, but all that can fail if there is mismatch between the facilities and individuality of students and lecturers (Nawaz et al., 2011a).

\subsection{Virtual Learning}

Virtual learning (VL) dates back to 1840, when Sir Isaac Pitman, the English inventor of shorthand, came up with the idea of delivering instruction via correspondence courses by mail. But only with the advances of modern technology has distance education grown to a multibillion dollar market (Dinevski \& Kokol, 2005). Virtual university (VU) at vu.edu.pak is the best example of virtual learning with zero-physical contact but virtually 100percent connected with its e-Students. The VU is a 'university without walls', an unpacked virtual institution thus 'The University' as an institution, seizes to exist. Where content and instructions are delivered through Internet, intranet, extranet, satellite TV, and CD-ROM with multimedia capabilities (Manochehr, 2007). The university, then, becomes far more externally oriented; an intermediary on the global stage, acting as collaborator, client, contractor and broker of higher education services (Goddard \& Cornford, 2007) 


\section{4 e-Learning 2.0}

The shift from Web 1.0 to Web 2.0 has also lifted e-Learning to e-Learning 2.0. From this perspective, traditional e-Learning systems used instructional packets to deliver to the students through Internet. The traditional learning consisted of readings and preparing assignments, evaluated by the teachers. In e-Learning 2.0, the new e-Learning places increased emphasis on social learning, collaboration and use of social software such as blogs, wikis, podcasts and virtual worlds like, 'Second Life' 'WebTrain' etc. The first 10 years of e-Learning (e-Learning 1.0) was focused on using the internet to reproduce the instructor-led knowledge where content was designed to lead a learner through the content. E-Learning 2.0, on the other hand, is built around collaboration because it assumes that knowledge is socially constructed (Wikipedia, 2011).

\section{Threats and Challenges}

"More than half of all information technology projects become runways overshooting their budgets and timetables while failing to deliver on their goals (McManus \& Wood-Harper, 2004:3)." Similarly, "While networked learning is making its appearance in universities, its overall impact is, as yet, rather limited (Baumeister, 2006)." Several researchers have identified the problems for the development, use and integration of ICTs into teaching, learning and educational management (Sife et al., 2007; Qureshi et al., 2009; Nawaz et al., 2011c).

\subsection{Development and Implementation Issues}

E-Learning is not merely another medium for the transmission of knowledge but that it changes the relationship between the teacher or trainer and learner. It requires new skills, competencies and attitudes amongst those planners, managers, teachers and trainers who are going to design and develop materials and support learners online. Thus, the development of innovative practices and the generation of new competencies in eLearning are fast becoming key issues (Gray et al., 2003). The focus is frequently placed on design and developing ICT-based environments and insufficient attention is given to the delivery process (McPherson \& Nunes, 2004).

University constituents hold differing perceptions and attitudes about the role of technology in the classroom and at the same time power structures in higher education, and insufficient communication among the various groups present obstacles to real technological and educational development (Juniu, 2005). There is evidence on the fact that during the e-Learning project development very little communication occurs between users and ICT professionals or developers. In the development practices, people feel that they are increasingly controlled by machines and that the human factors of their work are disappearing. They find loosing their privacy and unsure about the security of data and information (Nawaz et al., 2011a).

\section{a. Lack of Local Research}

The main reason for the gap between theory and practice is the 'Lack of Research' about the domestic environment to record the local context, user views and requirements and thereby plan accordingly. The issue of lack of research in Pakistan is frequently discussed 
in academic institutions with lack of funding and facilities are presented as the major reasons for the problem. Whatever the reason, it is not possible to harness new ICTs without first measuring the pulse of local context (Memon, 2007; Hameed, 2007). The researchers report over and over that technology integration in any context depends on how the technology fits into the existing social purposes and practices of a community (Koo, 2008). Similarly, HEC's website asserts that "The leveraging of ICT to support higher education reform and the development of a research culture in Pakistani universities is essential (HEC, 2011)."

\section{b. Borrowed Models of e-Learning}

Developing countries commonly trend to follow the tracks of development in the developed world. However, Walsham (2000:105), a noted researcher in information systems, argues that "the approaches taken from the industrialized countries may not transfer effectively to the different environments of the developing countries." The research confirms that an e-Learning model in US can be implemented in some Asian country with the expectations of same results (Mokhtar et al., 2007; Koo, 2008). There are several differences in the context of both the countries. The developing countries are borrowing foreign models which are also foreign to their environment therefore; the wanted results are emerging neither in volume nor in quality unless a contextual rethinking is accelerated (Nawaz et al., 2011b).

\section{c. Lack of User-Participation}

As research suggests, the biggest hurdle in contextualizing the e-Learning environments is the lack of participation in the development trajectory of eProjects. The projects mismatch the context because the users are not contacted thoroughly to explain different aspects of their context before the developers who can then embed these user requirements into the new digital systems. Lack of user is reported around the world. Users lodge complaints about their deprivation from having a say in the eLearning eLearning systems which are supposed to be used by them. The problem is more sensitive and touchy in developing countries where demographic differences are far more tense and implicative. There are many problems for this lack of user participation including demographic differences and diversities in perceptions and attitudes about ICTs, their development and uses (Nawaz, 2011; Nawaz, 2012c).

\subsection{Use and User Concerns}

Given the differences of perceptions (Young, 2003) users behave differently while using the e-Learning tools and techniques for teaching and learning purposes. A key challenge for institutions is overcoming the cultural mindset whereby departments and individuals act as silos, keeping information and control to themselves (LaCour, 2005). Moreover, the training that educators do receive does not always match with their educational needs, because the faculty is rarely involved in the decisions about technology and design of new strategies for technology-integration (Juniu, 2005). In developing countries, ICTs have not permeated to a great extent in many higher learning institutions in most developing countries due to many socio-economic and technological circumstances (Qureshi et al., 2009). 
System Compatibility: The greatest challenge in learning environments is to adapt the computer-based system to differently skilled learners. If the environment is too complex the user will be lost, confused or frustrated. On the other hand, too simple or nonsystematic environments cause motivational problems (Sirkemaa, 2001). Technology is by nature disruptive, and so, demands new investments of time, money, space, and skills and changes in the way people do things (Aaron et al., 2004). Furthermore, face-to-face communication is critical for classroom social relationships and interpersonal processes while, online technologies have reduced support for social interaction. Although emotions can be conveyed through e-mail or chatting, it does not replace the fundamentals of our socio-emotional well-being (Qureshi et al., 2009). Thus, the barriers can make technology use frustrating for even the technological experts (Nawaz et al., 2011a).

Dependence on Technical Department and Professionals: Nawaz \& Qureshi (2010a) note that a very critical problem in the use of e-Learning is the dependence of teachers, students and administrators on the ICT-department or technical support needed by the users across the using process. Similarly, users do not only depend on ICT staff for technological support but also face pressures from the pedagogues to demonstrate the role of technology in supporting constructive, authentic, and cooperative learning. Research suggests that only the technology training cannot ensure better use of new tools, users also need continuous technical and human resource support for technology integration (Nawaz et al., 2011c).

Change Management: Within universities, the implementation of ICT is not an easy task for instance, decision makers and academics are sometimes reluctant to change curricula and pedagogic approaches; teaching staff and instructors lack incentive and rewards in a system where professional status and career trajectories are based on research results rather than pedagogic innovation (Loing, 2005). There are many obstacles for implementation of the ICT in universities. Some of them are classical, as are e.g. inertia of behavior of people, their resistance to changes, etc. If the ICT should serve properly, it should enforce an order in all folds of the university life. People who loose their advantage of the better access to information have a fear from order (Nawaz et al., 2011c).

Individual Challenges: Technological change is not perceived as a collective experience rather a personal challenge therefore, solutions to the problem of integrating technological innovations into the pedagogy are more focused on the individual teachers (Sasseville, 2004). Some teachers are strongly advocate the technological innovation but may resist in accepting technology as an integral part of the learning process. These divergent reactions and concerns have thus created a continuum that represents various attitudes towards technology (Juniu, 2005). Similarly, inexperience may lead to developing learners' anxiety (Moolman \& Blignaut, 2008; Nawaz, 2011).

Political Sustainability: Political sustainability refers to the acceptance of new system by the administrators handling the policy and leadership matters in the universities (Tinio, 2002). Particularly, in a bottom up approach, the grass-roots may be better placed to understand and implement innovation, but there can be a lack of physical and political support (Aaron et al., 2004). There is a lack of feedback towards higher levels of decision and general policy, and little impact on strategy definition and implementation thereby 
creating resistance on the part of administrators to help and cooperate (Nawaz \& Qureshi, 2010b).

\subsection{The Contemporary Scenario}

a. Gaps between Theory and Practice of e-Learning

There are several gaps between whatever is presented in theory and what happens in reality and this is evident at all levels of governments, institutions, groups and individuals in the e-Learning environments of developed and developing countries including the HEIs of Khber Pakhtunkhwa province of, Pakistan. For example, "when formulating policy, administrators tend to favor the reformist approach, but in practice they are generally technocratic (Sahay, 2004)." Thus, "there is a gap between the rhetoric about information society and knowledge economy on the one hand, and the practical approach to ICT and its implementation at institutional level on the other hand (Loing, 2005)."

\section{b. Multiplicity of Digital-Divides}

The multiplicity of perceptions, theories, and attitudes of users towards ICTs creates digital divides within the environment of higher education (Juniu, 2005). Those who support technology, they seek for it and therefore reduce the impacts of digital divide for them. But the users who are don't the support technology; they adopt ICTs passively thereby widening the digital divide for them. The digital divide classifies the individuals, communities, cultures and nations in terms of access to ICTs, Internet and online resources (Moolman \& Blignaut, 2008; Nawaz, 2012a).

The digital divide in higher education refers to the "division of knowledge, expectations, and needs that, in turn, influences the access to information about what technology works, what technology is needed, and how such technology should be integrated in the classroom (Juniu, 2005)." A commonsense approach to overcoming this gap is to develop sustaining partnerships among students, faculty, academic computing staff, and administrators (Kopyc, 2007).

\section{c. Failure to Catch-up with Paradigm-Shifts}

Connected with the preceding point of digital divide, we are still stuck with the old methods of teaching, learning and educational management. The "traditional institutions are obviously not in a position to cope with this growing demand in any systematic way (Baumeister, 2006)", our teaching is still teacher-centered and student-centric pedagogy is yet in the documents and theory or at the most in discussions. The market is changing fast but our education system, particularly higher education is not catching up with the emerging demands of information society. In Pakistan the gap between the technological skills needed for the new economy and the traditional education institutions are increasing fast (Nawaz et al., 2011a).

\section{Opportunities}

Education determines, more than anything else, a country's prospects for human development and competitiveness. Fortunately, the information revolution offers some 
extraordinary opportunities in education. Common sense tells us that we should teach different learners differently. Parents demonstrate this intuitive wisdom when they communicate differently to their children according to their specific ages (Dinevski \& Kokol, 2005). Universities and even smaller departments within organizations are becoming capable to afford sophisticated digital systems (Ezziane, 2007). Electronically supported processes in the teaching and administrative spheres do not seem to be displacing traditional ways of doing things. Rather, the outcomes are often a matter of the new 'virtual' and the old 'traditional' notions of the university co-existing in a tense relationship (Qureshi et al., 2009).

\subsection{Global Availability of ICTs}

The developing countries are not supposed to produce hardware because firstly, hardware is becoming inexpensive as well as a huge number of 'Branded Computers' are transported to the developing and poor countries, which are hi-tech but very cheap in comparison to the new computers of same model and specifications. So availability of hardware is not a big deal in the developing world. Similarly, software is also available not through standard channels rather piracy but with the inception of Web 2.0 and FOSS, it is gradually becoming very cheaper for the developing countries to capitalize on the free of cost software that is available online and which is also coming in a variety to serve different purposes of applications in the teaching, learning and administrative functions in the HEIs (Kundi \& Nawaz, 2010).

\subsection{Free and Open Sources Systems (FOSS)}

The history of social software is as long as the history of computers itself, for example, it took the Web less than four years to attract 50 million users while radio needed almost 40 years to gain the same number of users (Mejias, 2006). While some research material has been available electronically from the first days of the Internet, libraries are putting more and more material on the Web and thus becoming virtual libraries. For example, the University of Texas made a move toward a bookless library system by posting 60,000 volumes online and trying to bring all their collections online (Snow, 2006). Carey \& Gleason (2006) note that open source systems are becoming culture in the HEIs, for example, in the February 2006 survey of U.S. higher education chief information officers (CIOs), it was found that two-third of the CIOs have either adopted or seriously planning in the favor of FOSS.

\subsection{Local ICT Industry and ICT-Professionals}

The biggest opportunity available to them is the growth of local ICT professionals who are basic to the successful use of new technologies. Pakistan can capitalize on its 'local ICT resources' to bring digital revolution. During the last decade Pakistan is taking visible steps in this regard. A huge amount of money has been invested in computerizing the HEIs to produce local ICT professionals, which are indispensable like infrastructure (Hameed, 2007). Given the benefits of using ICTs in educational business, all the nations are trying hard to digitize thereby casting mounting pressure on the HEIs to play active role by making local availability of knowledge and skills and, as a result, regionally engaged universities can become a key local and national powerhouse for development, 
especially in less developed regions of the globe (Goddard \& Cornford, 2007). HEIs in Pakistan are generating more than 6000 ICT-Graduates annually (HEC, 2011).

\subsection{Local/ National/ and International/ Partnerships}

The use of new collaborative technologies requires team work more than we are used to. Networking and social software helps users in working collaboratively while still preserving their personal preferences and styles (Juniu, 2005). The collaboration requires partnerships between the university constituents (teachers, students and administrators) as well as at the national (partnerships between the universities and public and private sector) (Baumeister, 2006) and international partnerships between world organizations and states (Tinio, 2002; Kopyc, 2007). For example, the emergence of a strong Indian IT industry happened due to concerted efforts on the part of the Government, and host of other factors like private initiatives, emergence of software technology parks, and public private partnerships (Nawaz et al., 2011c).

\subsection{Growth of Information-Society/Culture}

The shift from traditional modes of life to modern life styles is characterized by several new dimensions. The traditional societies are turning into information and knowledge societies' where societies are switching from isolated stance to global and collaborative trends at the global level with collaboration as a critical norm in the culture (Valcke, 2004). Our world's culture is no longer only literary and artistic, it is also technologic and scientific and at the crossroads of these two aspects, refusing this would reflect the inability to integrate into modern societies (Sasseville, 2004). ICTs have created new societies, which are discussed under different concepts including 'information societies' (Sasseville, 2004; McPherson \& Nunes, 2004); knowledge societies (Aviram \& EshetAlkalai, 2006; Klamma et al., (2007); and open information society with knowledge economy (Hameed, 2007). The higher education commission (2011) aims to ensure that a comprehensive ICTs strategy is implemented to develop a knowledge-society in Pakistan.

\section{Methodoly \& Theoretcal Model}

The relevant secondary sources were thoroughly exhausted and critical analysis and argumentation was applied in drawing the findings and conclusion. Through the study logical argumentation and critical analysis of the data was employed. Based on the data, major variables were extracted.

The theoretical model of this study given below in figure- 1 is based on the thorough investigation of the previous studies and literature both in the developed and developing countries. The review of the studies on e-Learning 1.0 to e-Learning 2.0 and earlier models presented time to time ignored some of the important aspects which might have strong influences and implications in the context of developing countries and especially in Pakistan. The factors that might play significant role in the implementation of eLearning 2.0 have been identified after exhausting the currently available literature. The model is developed to investigate the role and influence of these factors in the promotion or hindrance of the successful e-Learning 2.0. 


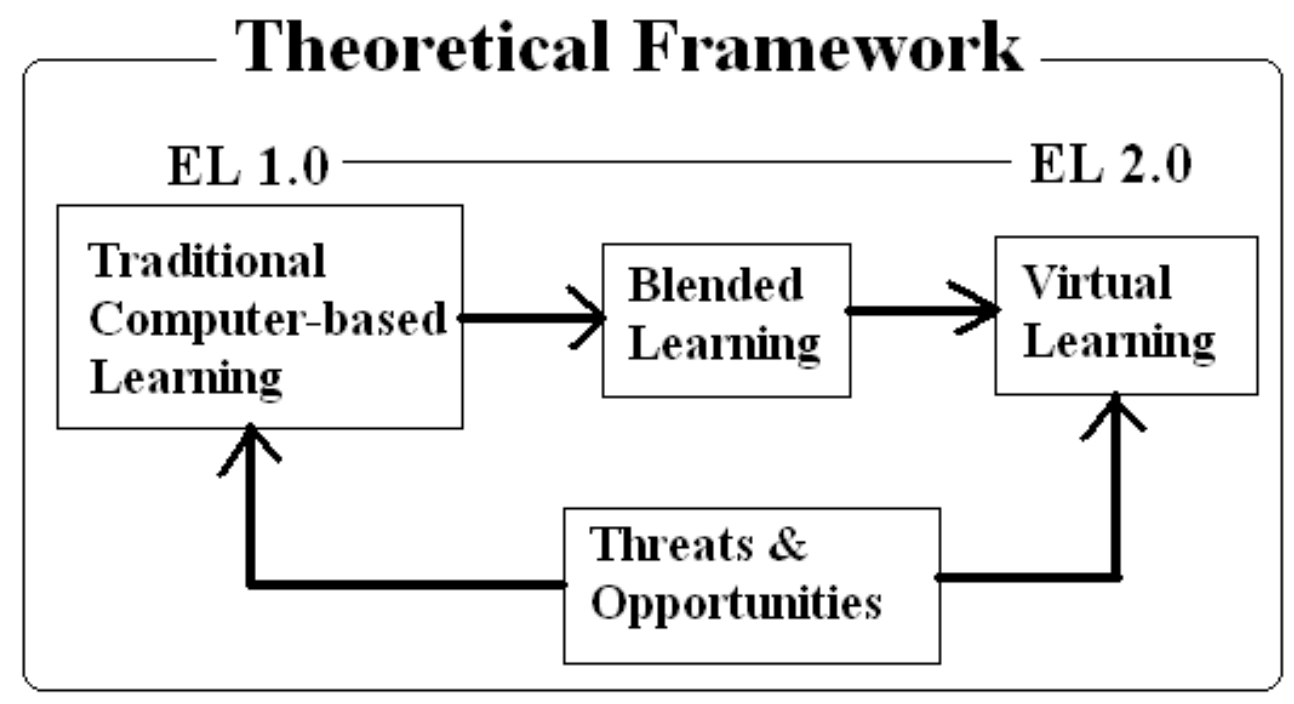

\section{Discussion and Conclusions}

There are both internal and external challenges and problems for the development and use of e-Learning options in HEIs. The research studies are constantly identifying problems relating to ICTs, approaches and methods for their uses, design and development methods, and the changing trends in these areas. Teachers, students and administrators are facing common as well as different challenges as are the developing and developed countries. it is however, widely reported and broadly accepted that it is not the technology, which is a problem rather the human, social and political problems make or break the digital opportunity initiatives in any organization including the HEIs. Asian Development Bank (2005) in its Evaluation of SAP:PAK 2005-2008 for the Social Sectors in Pakistan reports that "there has been no shortage of well-intentioned policies, strategies, and targets for improving social sector performance in Pakistan, but the level of policy implementation and attainment has been extremely limited."

The literature review deals with the contents and role of contextual factors in the development and use of e-Learning facilities in HEIs of the world. Several researchers have underlined the challenges associated with the context of e-Learning (Aaron et al., 2004; Loing, 2005; Macleod, 2005; Baumeister, 2006; Stephenson, 2006; Hameed, 2007; Nawaz et al., 2011a,d). The central theme of all these contextual contents is that eLearning tools and techniques can only be used effectively if their development and use is compatible with the all the contextual elements of the workplace where users practically use the technologies. This concern is very well supported by this research as 
almost all the statistical analysis on the relationships between different factors of eLearning development and use reveal that the interdependencies are networked.

Almost every researcher in the field of e-Learning have identified 'top-managementsupport' as a critical factor in the success or failure of an e-Project for HEIs all over the globe. The support and facilitation from government is on the top but once the government is taking interest then the commitment and involvement of the top management within every institution makes the difference. Tinio (2002) asserts that the role of top management is central in the integration of ICTs in education because many teacher or student-initiated e-Learning projects have failed due to the lack of support from above. Furthermore, for a sustainable development, administrators must learn using technology as well as understand the "technical, curricular, administrative, financial, and social dimensions of ICT use in education." What ensures the successful implementation of a strategic plan for educational technology is the "assurance of support from the senior administrative level (Stockley, 2004)"

The provision of a robust ICT-based infrastructure is challenging in the sense that it is not a one-shot activity. It is not like that the technical resources are purchased once for all. Computer-technologies are rapidly changing, which require 'Updates' by the institutions otherwise they will lag behind fellow and competitive institutes in technological sophistication. So creation, maintenance and updating of technical infrastructure is a process which continues for ever. Furthermore, while developing and/or updating, most of the HEIs opt for cutting-edge technologies however, experience shows that mostly these 'leading-edge technologies turn into bleeding-edge technologies' by eating up budgets and delivering nothing special. Therefore researchers suggest that "go with tried and tested systems (Tinio, 2002)." At the same time latest digital options are expensive while, "the time is right for collaborative action because the time is wrong for any approach other than cost-sensitive, resource-smart deployments (Klonoski, 2005)."

The significance of user participation in the development and use of e-Learning is the main route to contextualizing the new technologies. When users are not heard, the developers mostly embed their self-conceived user-perceptions into the system, which then appear incompatible with the real user-demands. Thus, in the context of eLearning e-Learning projects, "user empowerment is the granting of unprecedented decisionmaking powers to the primary agents in education: teachers and students (Reilly, 2005). The appointment of 'Role Models from the User-groups' will work as a disciplinary insiders or faculty peers in their home departments and motivate their colleagues through discourse on the advantages of ICTs for users.

\section{Future Research}

There is growing trend of merging the traditional teaching to e-Learning 2.0 an open, social medium of teaching through application of all available Web 2.0 applications as they themselves are growing rapidly. These changes could be of two types i.e. 1. Change in didactical design i.e. changes in the concepts e.g. use of Web 2.0 for eLearning 2.0 instead of its application for traditional lectures, and 2. Designing the system of education e.g. Change in the system of education, familiarity of the 
learners and teachers with new concepts. Though, e-Learning 2.0 is a buzzword for the new generation of developing nations like Pakistan us ing internet, however, for the sake of future developments, this research suggest that future research studies should be focused on the following:

- $\quad$ The research studies already undertaken on e-Learning 1.0 should be the prerequisite for all subsequent steps.

- New applications 'Web 2.0' should be developed with ease and good usability for future developments in technology based education.

Development and use of didactical concepts and tools that may help us to rethink and restructure our education.

\section{References}

Aaron, M., Dicks, D., Ives, C., \& Montgomery, B. (2004). Planning for integrating teaching technologies, Canadian Journal of Learning and Technology, 30(2), Spring. Available: URL: http://www.cjlt.ca/. Accessed: January 23, 2012.

ADB (2005). Sector assistance program evaluation for the social sectors in Pakistan SAP: PAK 2005-08 (July). Operations evaluation department. Asian Development Bank. Available: http://www.adb.org/ Evaluation/methods.asp. Accessed: September 27, 2011.

Aviram, A., \& Eshet-Alkalai, Y. (2006). Towards a theory of digital literacy: Three scenarios for the next steps, European Journal of Open, Distance and E-Learning, Available: http://www.eurodl.org/. Accessed: September 27, 2011,

Baumeister, H. (2006). Networked learning in the knowledge economy - A systemic challenge for Universities, European Journal of Open, Distance and E-Learning, Available: http://www.eurodl.org/. Accessed: December 12, 2012.

Brwon, S., Adler, J., \& Richard, P. (2008). Minds on fire: Open education in long tail and learning 2.0, Educause Review (Jan/Feb), 16-32.

Carey, P., \& Gleason, B. (2006). Vision 2010: The future of higher education business and learning applications, Innovate Journal of Online Education, 3(1). Oct/Nov. Available: http://Innovateonline.info. Accessed: April 10, 2011.

Crane, Beverley, E. (2009). Using Web 2.0 tools in the K-12 classroom, Neul-Shuman Publishers Inc, p.3.

Dinevski, D., \& Kokol, D. P. (2005). ICT and lifelong learning, European Journal of Open, Distance and E-Learning. Available: http://www.eurodl.org/. Accessed: September 27, 2011.

Downes, S. (2006). E-Learning 2.0, eLearning Magazine, 29(1). Available: http://www.elearnmag.org/subpage.cfm?section=articles\&article=29-1. Accessed: January, 12, 2012.

Ezziane, Z. (2007). Information technology literacy: Implications on teaching and learning, Journal of Educational Technology \& Society, 10 (3), 175-191. Available: http://www.ask4research.info/. Accessed: April 10, 2011.

Goddard, J. B., \& Cornford, J. (2007). The University, ICTs and development in the information society. Available: http://www.lirne.net/resources/ netknowledge/goddard.pdf. Accessed: July 21, 2011.

Gray, D. E., Ryan, M., \& Coulon, A. (2003). The training of teachers and trainers: Innovative practices, skills and competencies in the use of e-Learning, European Journal of Open, Distance and E-Learning. Available: http://www.eurodl.org/. Accessed: August 9, 2011. 
Hameed, T. (2007). ICT as an enabler of socio-economic development. Available: http://www.itu.int/osg/spu/digitalbridges/ materials/hameed-paper.pdf. Accessed: September 27, 2011.

Higher Education Commission (HEC) (2011). E-Reforms: PERN, PRR, e-Learning, CMS \& Digital Library. Available: http://www.hec.gov.pk/new/ eReforms/eReforms.htm. Accessed: July 11, 2011.

Juniu, S. (2005). Digital democracy in higher education bridging the digital divide, Innovate Journal of Online Education, 2(1), October/November. Available: http://Innovateonline.info. Accessed: August 9, 2011.

Klamma, R., Chatti, M. A., Duval, E., Hummel, H., Hvannberg, E. H., Kravcik, M., Law, E., Naeve, A., \& Scott, P. (2007). Social software for life-long learning, Journal of Educational Technology \& Society, 10 (3), 72-83.

Klonoski, E. (2005). Cost-saving collaboration: Purchasing and deploying a statewide learning management system, Innovate Journal of Online Education, 1(4), April/May. Available: http://Innovateonline.info. Accessed: September 27, 2011.

Koo, A. C. (2008). Factors affecting teachers' perceived readiness for online collaborative learning: A case study in Malaysia, Journal of Educational Technology \& Society, 11 (1), 266278.

Kopyc, S. (2007). Enhancing teaching with technology: Are we there yet? Innovate Journal of Online Education. December 2006/January 2007, 3(2). Available: http://Innovateonline.info. Accessed: April 10, 2011.

Kundi, G. M., \& Nawaz, A. (2010). From objectivism to social constructivism: The impacts of information and communication technologies (ICTs) on higher education. Journal of Science and Technology Education Research (JSTER), 1(2), 30-36.

LaCour, S. (2005). The future of integration, personalization, and ePortfolio technologies, Innovate Journal of Online Education, 1(4), April/May. Available: http://Innovateonline.info. Accessed: September 27, 2011.

Loing, B. (2005). ICT and Higher Education. General delegate of ICDE at UNESCO. 9th UNESCO/NGO Collective Consultation on Higher Education (6-8 April 2005). Available: http://ong-comite-liaison.unesco.org/ongpho/acti/3/ 11/rendu/20/pdfen.pdf. Accessed: June 24, 2011.

Macleod, H. (2005). What role can educational multimedia play in narrowing the digital divide? International Journal of Education and Development using ICT, 1(4). Available: http://ijedict.dec.uwi.edu//. Accessed: August 9, 2011

Manochehr, N. (2007). The influence of learning styles on learners in E-learning environments: An empirical study, Computers in Higher Education and Economics Review, Vol. 18. Available: http://www.economicsnetwork. ac.uk/cheer.htm. Accessed: April 10, 2011.

McManus, J., \& Wood-Harper, T. (2004). Information systems project management: Methods, tools and techniques. Pearson Education, Limited, UK.

McPherson, M., \& Nunes, M. B. (2004). The role of tutors as an integral part of online learning support, European Journal of Open, Distance and E-Learning. Available: http://www.eurodl.org/. Accessed: July 21, 2011.

Mejias, U. (2006). Teaching social software with social software, Innovate Journal of Online Education, 2(5), June/July. Available: http://Innovateonline.info. Accessed: April 10, 2011.

Memon, G. R. (2007). Education in Pakistan: The key issues, problems and the new challenges, Journal of Management and Social Sciences, 3(1), 47-55. Spring. Mokhtar, S. A., Alias, R. A., \& Abdul-Rahman, A. (2007). Academic computing at Malaysian colleges, International Journal of Education and Development using ICT, 3(2). Available: http://ijedict.dec.uwi.edu//. Accessed: September 27, 2011. 
Moolman, H. B., \& Blignaut, S. (2008). Get set! e-Ready, ... e-Learn! The e-readiness of warehouse workers, Journal of Educational. Technology \& Society, 11 (1), 168-182.

Nawaz, A. (2011). Users' training: The predictor of successful e-Learning in HEIs, Global Journal of Computer Science \& Technology, 11(4), 1-8.

Nawaz, A. (2012a). Metaphorical interpretation of e-Learning in higher education institutions, Journal of Advances in Information Technology, 3(1):1-9, February.

Nawaz, A. (2012b). Investigating change management for implementing e-Learning projects in higher education, International Journal of Research and Business Management, 1(9), 1-11.

Nawaz, A. (2012c). E-Learning experiences of HEIs in advanced states, developing countries and Pakistan, Universal Journal of Education and General Studies,. 1(3), 072-083, March..

Nawaz, A., \& Kundi, G. M. (2010a). Predictor of e-learning development and use practices in higher education institutions (HEIs) of NWFP, Pakistan, Journal of Science and Technology Education Research, 1(3), 44-54.

Nawaz, A., \& Kundi, G.M. (2010b). Sustained technical support: Issues \& prospects for eLearning in HEIs. Malaysian Journal of Distance Education, 12(2), 61-77.

Nawaz, A., \& Kundi, GM. (2010b). Digital literacy: An analysis of the contemporary paradigms, Journal of Science and Technology Education Research. 1(2), 19-29.

Nawaz, A., \& Qureshi, AQ. (2010). E-teaching/E-pedagogy: Threats \& opportunities for teachers in HEIs, Global Journal of Management \& Business Research, 10(9), 23-31.

Nawaz, A., Awan, Z., \& Ahmad, B. (2011c). Integrating educational technologies in higher education of the developing countries, Journal of Education and Practice, 2(2).

Nawaz, A., Najeebullah, \& Miankheil, A. (2011a). Challenges of e-teaching: Contemporary paradigms and barriers, Research Journal of Information Technology, 3(2), 99-107.

Nawaz, A., Qureshi, Q .A., \& Sattar, A. (2011b). Demographic prediction of e-Learning development and use practices in HEIs of KPK, Pakistan Journal of Applied Social Sciences, 1(1), 58-69.

O'Reilly, T. (2005). What is Web 2.0-Design patterns and business models for the next generation software, available: http://www.oreilly.com/pub/a/oreilly/tim/news/2005/09/30/what-is-web20.html. Accessed: January, 12, 2012.

Qureshi, Q.A., Ahmad, S., Najibullah., Nawaz, A., \& Shah, B. (2009). e-Learning development in HEIs: Uncomfortable and comfortable zones for developing countries, Gomal University Journal of Research, 25(2), 47-56.

Reilly, C. (2005). Teaching by example: A case for peer workshops about pedagogy and technology, Innovate Journal of Online Education, 1(3), February/March. Available: http://Innovateonline.info. Accessed: November 13, 2011.

Sahay, S. (2004). Beyond utopian and nostalgic views of information technology and education: Implications for research and practice, Journal of the Association for Information Systems, 5(7), 282-313.

Sandall, P., Ceccucci, W., \& Peslak, A. (2008). Web 2.0 matters: An analysis of implementing Web 2.0 in the classroom, Information System Education Journal, 6(64).

Sasseville, B. (2004). Integrating information and communication technology in the classroom: A comparative discourse analysis, Canadian Journal of Learning and Technology, 30(2), Spring. Available: http://www.cjlt.ca/. Accessed: April 10, 2011.

Shimabukuro, J. (2005). Freedom and empowerment: An Essay on the next step for education and technology, Innovate Journal of Online Education, 1(5), June/July. Available: http://Innovateonline.info. Accessed: September 11, 2011.

Sife, A. S., Lwoga, E. T., \& Sanga, C. (2007). New technologies for teaching and learning: Challenges for higher learning institutions in developing countries, International Journal of 
Education and Development using ICT, 3(1). Available: http://ijedict.dec.uwi.edu//. Accessed: September 27, 2011.

Sirkemaa, S. (2001). Information technology in developing a meta-learning environment, European Journal of Open, Distance and E-Learning, Available: http://www.eurodl.org/. Accessed: August 9, 2011.

Snow, E. (2006). Teaching students about Plagiarism: An internet solution to an internet problem, Innovate Journal of Online Education, 2(5), June/July. Available: http://Innovateonline.info. Accessed: July 23, 2011.

Stephenson, R. (2006). Open source/open course: Learning lessons for educators from free and open source software, Innovate Journal of Online Education, 3(1), Oct/Nov. Available: http://Innovateonline.info. Accessed: April 10, 2011.

Stockley, D. (2004). Strategic planning for technological innovation in Canadian post-secondary education, Canadian Journal of Learning and Technology, 30(2), Spring. Available: http://www.cjlt.ca/. Accessed: September 27, 2011.

Tinio, V. L. (2002). ICT in education. Presented by UNDP for the benefit of participants to the World Summit on the Information Society. UNDP's regional project, the Asia-Pacific Development Information Program (APDIP), in association with the secretariat of the Association of Southeast Asian Nations (ASEAN). Available: http://www.apdip.net/publications/iespprimers/eprimer-edu.pdf. Accessed: April 10, 2011.

Valcke, M. (2004). ICT in higher education: An uncomfortable zone for institutes and their policies. In R. Atkinson, C. McBeath, D. Jonas-Dwyer \& R. Phillips (Eds), Beyond the comfort zone: Proceedings of the 21st ASCILITE Conference (pp. 20-35). Perth, 5-8 December. Available: http://www.ascilite.org.au/conferences/ perth04/procs/valcke-keynote.html. Accessed: July 23, 2011.

Walsham, G. (2000). IT/S in developing countries. In: Zeleny, Milan (editor) The IEBM handbook of information technology in business. Business Press, Thomson Learning. pp, 105-109.

Wikipedia (2011) e-Learning. Available: http:// www. Wikipedia. org/. Accessed: April 7, 2011.

Young, L. D. (2003). Bridging theory and practice: Developing guidelines to facilitate the design of computer-based learning environments, Canadian Journal of Learning and Technology, 29(3), Fall/Autumn. Available: http://www.cjlt.ca/. Accessed: August 19, 2011. 